\title{
Simulation of the crystal growth of platelet sea ice with diffusive heat and mass transfer
}

\author{
Pat WONGPAN, ${ }^{1}$ Patricia J. LANGHORNE, ${ }^{1}$ David E. DEMPSEY, ${ }^{1,2}$ \\ Lisa HAHN-WOERNLE, ${ }^{1,3,4}$ Zhifa SUN ${ }^{1}$ \\ ${ }^{1}$ Department of Physics, University of Otago, Dunedin, New Zealand \\ E-mail: pat.wongpan@postgrad.otago.ac.nz \\ ${ }^{2}$ Los Alamos National Laboratory, Los Alamos, NM, USA \\ ${ }^{3}$ ETH Zürich, Zürich, Switzerland \\ ${ }^{4}$ Utrecht University, Utrecht, The Netherlands
}

\begin{abstract}
Antarctic coastal sea ice often grows in water that has been supercooled by interaction with an ice shelf. In these situations, ice crystals can form at depth, rise and deposit under the sea-ice cover to form a porous layer that eventually consolidates near the base of the existing sea ice. The least consolidated portion is called the sub-ice platelet layer. Congelation growth eventually causes the subice platelet layer to become frozen into the sea-ice cover as incorporated platelet ice. In this study, we simulate these processes in three dimensions using Voronoi dynamics to govern crystal growth kinetics. Platelet deposition, in situ growth and incorporation into the sea-ice cover are integrated into the model. Heat and mass transfer are controlled by diffusion. We extract and compare spatial-temporal distributions of porosity, salinity, temperature and crystallographic c-axes with observations from McMurdo Sound, Antarctica. The model captures the crystallographic structure of incorporated platelet ice as well as the topology of the sub-ice platelet layer. The solid fraction, which has previously been poorly constrained, is simulated to be $\sim 0.22$, in good agreement with an earlier estimate of $0.25 \pm 0.06$. This property of the sub-ice platelet layer is important for biological processes, and for the freeboard-thickness relationship around Antarctica.
\end{abstract}

KEYWORDS: Antarctic glaciology, sea ice, sea-ice growth and decay, sea-ice modelling, sea-ice/ice-shelf interactions

\section{INTRODUCTION}

When sea water freezes, the resulting sea ice generally contains pure ice crystals, as well as brine and gas pockets. Granular ice, formed from the consolidation of a layer of tiny ice crystals at the air/ocean interface (Maus and De la Rosa, 2012; Naumann and others, 2012, and references therein), grows downwards, with faster growth on the crystal basal plane than in the c-axis direction (Hillig, 1959). The aspect ratio of this anisotropic growth, i.e. the growth rate in the basal plane divided by that in the $c$-axis direction, lies in the range 20-100 (Smedsrud and Jenkins, 2004; Kawano and Ohashi, 2009). Consequently, as the ice grows, geometric selection filters out the granular crystals with c-axes close to the vertical (Kolmogorov, 1949), and columnar ice is formed with $c$-axes lying close to the horizontal plane. We refer to the sea ice that forms by conduction of heat through the sea ice to the atmosphere as congelation ice.

Around the coast of Antarctica, sea ice often grows in water that has been supercooled by ocean-ice-shelf interactions (e.g. Lewis and Perkin, 1986). Tiny crystals exist within this supercooled water column. These crystals rise to the surface and deposit under the sea-ice cover to form a porous layer in an evolving state of consolidation. The least consolidated portion is called the sub-ice platelet layer (e.g. Fig. 1). Eventually heat loss to the atmosphere, as well as to the near-surface supercooled ocean, causes these crystals to become frozen into the sea-ice cover as incorporated platelet ice (Smith and others, 2001; Dempsey and others,
2010; Gough and others, 2012a). Platelet ice is therefore important because it is a surface expression of processes that take place deep in an ice-shelf cavity. These processes may influence sea-ice thickness (e.g. Hellmer, 2004) and extent (Bintanja and others, 2013). Further, because the sub-ice platelet layer is highly porous and provides a stable surface for algal attachment, it harbours some of the highest accumulations of sea-ice algae found anywhere on Earth (Arrigo and Thomas, 2004).

In addition, platelet ice influences the measurement of sea-ice thickness. There are three major techniques for obtaining sea-ice thickness: drilling, electromagnetic induction sounding, and airborne and satellite altimeter measurements (Haas and Druckenmiller, 2009). Within limitations posed by the snow-cover thickness, these methods are fairly well developed for congelation ice, particularly in the Arctic (Haas and Druckenmiller, 2009). Around regions of coastal Antarctica, on the other hand, the situation is further complicated due to the highly porous, sub-ice platelet layer. For electromagnetic induction thickness estimates, a value of the solid fraction of the sub-ice platelet layer is needed to constrain the electrical conductivity for the inversion algorithm. The solid fraction of this layer is also needed to derive sea-ice thickness from freeboard, using the assumption of hydrostatic equilibrium and altimeter measurements. Price and others (2014) have recently demonstrated that sea-ice thickness, derived from freeboard estimates, may be in error by up to $20 \%$ because of the presence of a sub-ice platelet layer. 


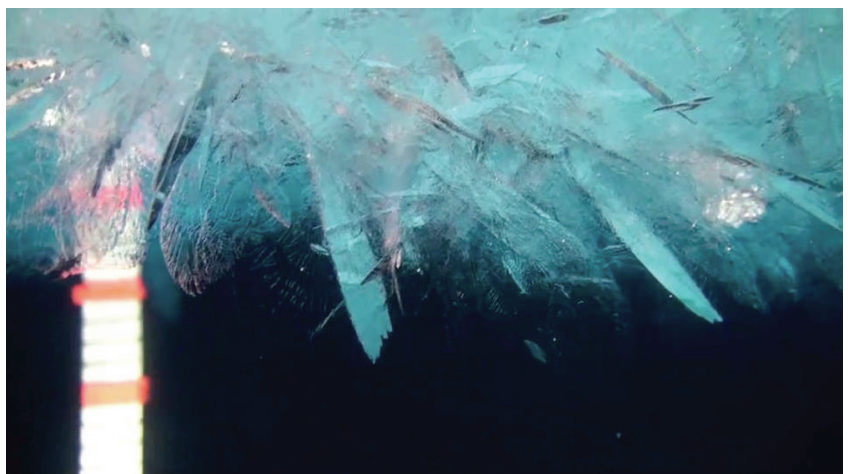

Fig. 1. The sub-ice platelet layer captured with an underwater camera (courtesy A.J. Gough and A.R. Mahoney). Note that the scale between the red lines is $0.05 \mathrm{~m}$.

It remains a challenge to directly measure the solid fraction by sampling. A variety of methods has been applied to obtain the solid fraction of the sub-ice platelet layer $\left(f_{s}\right)$, and Gough and others (2012a) have summarized typical estimates from several authors to be between 0.2 and 0.5 . The most accurate value to date is $f_{\mathrm{s}}=0.25 \pm 0.06$, based on the heat flux measurements of Gough and others (2012a).

One possible way to obtain this sub-ice platelet layer solid fraction is to simulate a number of ice platelets floating up from depth, being deposited and continuing to grow locally under the sea-ice cover. In short, it is a solidification problem. There are many methods available to solve this type of problem (e.g. the level set method (Tan and Zabaras, 2006), the phase field model (Kobayashi, 1993), cellular automata (Spittle and Brown, 1994) and smoothed particle hydrodynamics (Monaghan and others, 2005)). The accuracy of those models is superb, but the complexity of the mathematics and the demand on computational resources are also at a high level, especially for simulations in three dimensions (3-D). Taking these factors into account, Voronoi dynamics (Ohashi and others, 2004) is a flexible and simple but efficient method to simulate the physical processes of interest here. This technique divides space into a set of points (or seeds) and for each seed there is a corresponding region consisting of all points closer to that seed than to any other. The construction of a set of rules allows crystal growth kinetics to be simulated.

Kawano and Ohashi (2006) performed such simulations in two dimensions (2-D) and report that their simulated value of brine area fraction from Voronoi dynamics, combined with salinity concentration in a 2-D domain, is higher than that of laboratory-grown sea ice. They point out that the missing dimension may cause loss of generality in their simulation. Their more recent paper (Kawano and Ohashi, 2009), in which heat conduction and salinity diffusion are included, is also limited to a 2-D approximation.

In an independent study, Dempsey (2008) and Dempsey and others (2010) used a purely mechanical model of Voronoi dynamics to simulate the accumulation and growth of platelet ice. Their results have some limitations, especially with regard to the lack of thermodynamic and fluid dynamic processes. Most importantly, the temporal evolution of solid fraction and the resulting salinity profile require thermodynamic implementation.

Recently, Hahn-Woernle (2011) introduced two simulations with the inclusion of heat and salt transport. The first is a

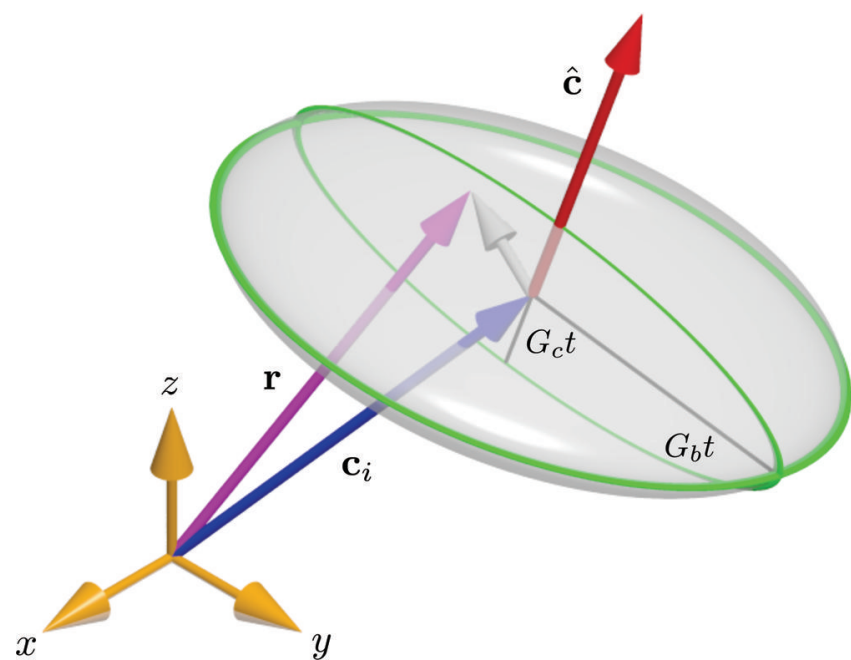

Fig. 2. An ice crystal is seeded at $\mathbf{c}_{i}$ with orientation or $c$-axis direction $\widehat{\mathbf{c}}$. $\mathbf{r}$ is a position vector relative to $x y z$ coordinates. $\mathbf{r}-\mathbf{c}_{i}$ (grey vector) represents a relative displacement from a certain position in space to the seeding position. $G_{c}$ and $G_{b}$ are growth functions in the $c$-axis direction and the basal plane, respectively.

one-dimensional Voronoi model which simulates the vertical growth of a sea-ice slab due to heat conduction through an air-ice-sea stack with varying thermal constants. The heat flux and salt diffusion can be monitored numerically. The second is a 2-D model of the growth of an individual platelet crystal through a vertical cut. Voronoi dynamics, including heat and salt constraints, was again used.

In this paper, we build a direct numerical simulation using Voronoi dynamics with diffusive heat and mass transfer. A 3-D model is necessary to understand the spectrum of growth processes in sea ice, and platelet ice in particular, starting from individual crystals in the water column and leading to the formation of a sub-ice platelet layer. Furthermore, we take into account the advancing interface, driven by heat loss to the atmosphere, and the deposition of ice crystals from the ocean to create different scenarios that imitate the natural process of incorporated platelet ice formation. In a similar process to taking a sea-ice core, we extract the solid fraction, temperature, salinity and crystal orientations from virtual sea-ice cores through the 3-D model domain, and compare the results to physical seaice cores retrieved from Antarctica.

\section{VORONOI DYNAMICS WITH DIFFUSIVE HEAT AND MASS TRANSFER}

The model is built in a $3-\mathrm{D}$ domain $\Omega(\mathbf{r}, t)$. This is discretized into cells and each cell has four 3-D matrices associated with it: solid fraction $\varphi(\mathbf{r}, t)$, characteristic number $K(\mathbf{r}, t)$, temperature $T(\mathbf{r}, t)$ and salinity $S(\mathbf{r}, t)$, where $\mathbf{r}=(x, y, z)$ and $t$ are the position vector and time respectively. $K(\mathbf{r}, t)$ identifies whether a cell is brine, ice-brine mixture or is labelled as an ice crystal to preserve its crystal orientation.

\section{Voronoi dynamics}

Consider a crystal $i$ with seed position $\mathbf{c}_{i}, c$-axis $\widehat{\mathbf{c}}$ and characteristic number $K_{i}$. The magnitude of the relative position $\left|\mathbf{r}-\mathbf{c}_{i}\right|$ of a point with position $\mathbf{r}$ in the domain $\Omega(\mathbf{r}, t)$ from position $\mathbf{c}_{i}$ (Fig. 2) is stored in the displacement 


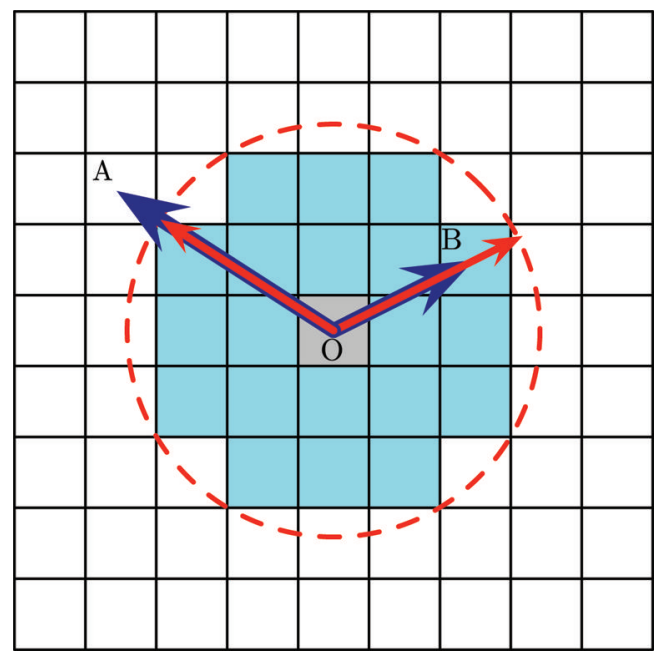

Fig. 3. To illustrate how Voronoi dynamics works, consider the liquid domain (white) in two dimensions. An ice cell (grey) is seeded at position $\mathrm{O}$ and it grows iteratively to form the connected ice cells (light blue) which we call the crystal. The displacement of other cells from cell $\mathrm{O}$ and the growth functions are calculated in advance and kept in the $\mathbf{R}$ and $\mathbf{G}$ matrices. At a certain time $t$, consider cells $A$ and $B$. Their displacement vectors $\overline{\mathbf{O A}}$ and $\overline{\mathbf{O B}}$ are drawn with blue vectors. Note that these two vectors are timeindependent. Their growth functions, describing the crystal growth kinetics, multiplied by time $(\mathbf{G} t)$ are represented by a red dashed contour which we call here the 'Voronoi front'. For cells of interest, we can construct red vectors from point $\mathrm{O}$ to this front and in the same direction as their displacement vector. These two vectors are compared for each cell. If the Voronoi dynamics condition $(\mathbf{R}-\mathbf{G} t<0)$ is satisfied and if the cell is adjacent to at least one ice cell, it can grow or flip to an ice cell at this time. Thus at the time illustrated, A remains liquid while B becomes solid.

matrix as

$$
R_{i}(\mathbf{r}) \equiv\left|\mathbf{r}-\mathbf{c}_{i}\right| .
$$

The Voronoi dynamics condition, which contains information about ice crystal growth kinetics,

$$
R_{i}(\mathbf{r})-G_{i}(\mathbf{r})\left(t_{i}+\Delta t_{\mathrm{V}}\right)<0,
$$

is well posed and ready to iterate (Fig. 3). $\Delta t_{V}$ is the time step for the Voronoi dynamics condition. In Eqn (2), $G_{i}(\mathbf{r})$ is the growth matrix of an ice crystal, which is defined as (Dempsey and others, 2010)

$$
G_{i}(\mathbf{r})=\frac{R_{i}(\mathbf{r})}{\sqrt{\left(\frac{R_{b}}{G_{b}}\right)^{2}+\left(\frac{R_{c}}{G_{c}}\right)^{2}}},
$$

where $R_{\mathrm{b}}$ and $R_{\mathrm{C}}$ are the magnitudes of the basal-plane and $c$-axis components of $\left|\mathbf{r}-\mathbf{c}_{i}\right|$, respectively. Similarly $G_{b}$ and $G_{C}$ are growth functions on the basal plane and along the $c$-axis. Except where crystals are deposited from the ocean, $G_{b}$ and $G_{c}$ are constant in this paper, i.e. $G_{b}=g_{b}$ and $G_{c}=g_{c}$, where $g_{b}$ and $g_{c}$ are growth rates on the basal plane and along the $c$-axis. The aspect ratio is defined as $\alpha \equiv g_{\mathrm{b}} / g_{\mathrm{c}}$ which is chosen such that geometrically an oblate spheroid crystal is grown with minor axis aligned with the c-axis as applied in Dempsey and others (2010). In addition, if we consider an advancing planar interface, the displacement and growth matrix are $z$ and $g_{\text {int }}=$ constant, respectively. The corresponding Voronoi dynamics condition is

$$
z-g_{\text {int }}\left(t+\Delta t_{\mathrm{V}}\right)<0 \text {. }
$$

Table 1. Parameters collected from Kawano and Ohashi (2009) and Hahn-Woernle (2011)

$\begin{array}{lccc}\text { Specific heat of solid } & C_{\mathrm{S}} & 2040 & \mathrm{~J} \mathrm{~kg}^{-1} \mathrm{~K}^{-1} \\ \text { Specific heat of liquid } & C_{\ell} & 4217 & \mathrm{~J} \mathrm{~kg}^{-1} \mathrm{~K}^{-1} \\ \text { Density of solid and liquid } & \rho_{\mathrm{s}} & 916.8 & \mathrm{~kg} \mathrm{~m}^{-3} \\ \text { Density of liquid } & \rho_{\ell} & 1000 & \mathrm{~kg} \mathrm{~m}^{-3} \\ \text { Thermal conductivity of solid } & k_{\mathrm{s}} & 2.0 & \mathrm{~J} \mathrm{~kg}^{-1} \mathrm{~K}^{-1} \\ \text { Thermal conductivity of liquid } & k_{\ell} & 0.6 & \mathrm{~J} \mathrm{~kg}^{-1} \mathrm{~K}^{-1} \\ \text { Thermal diffusivity in solid } & \kappa_{\mathrm{S}} & 9.80 \times 10^{-7} & \mathrm{~m}^{2} \mathrm{~s}^{-1} \\ \text { Thermal diffusivity in liquid } & \kappa_{\ell} & 1.42 \times 10^{-7} & \mathrm{~m}^{2} \mathrm{~s}^{-1} \\ \text { Latent heat } & \mathrm{L} & 334 \times 10^{3} & \mathrm{~J} \mathrm{~kg}^{-1} \\ \text { Liquidus slope } & \Gamma & 0.057 & { }^{\circ} \mathrm{C} \\ \text { Liquidus intercept } & T_{\mathrm{m}} & 0.0939 & { }^{\circ} \mathrm{C} \\ \end{array}$

\section{Heat conduction in an anisotropic medium with phase change}

We assume that the transport of heat is purely by thermal conduction which depends strongly on the various phases of the medium within the system. From Worster (1986), the governing equation of heat transfer is

$$
\overline{\rho c} \frac{\partial}{\partial t} T(\mathbf{r}, t)=\nabla \cdot(\bar{k} \nabla T(\mathbf{r}, t))+\rho_{\mathrm{s}} L \frac{\partial}{\partial t} \varphi(\mathbf{r}, t),
$$

where $T$ is temperature, $\varphi$ is solid fraction, $\rho$ is the averaged density, $c$ is the averaged specific heat, $L$ is the latent heat and $\rho_{\mathrm{s}}$ is the density of the solid. We also assume the solidfraction-weighted averages of these thermophysical properties, i.e. $\bar{X}=X(\varphi)=\varphi X_{\mathrm{s}}+(1-\varphi) X_{\ell}$ and $\overline{X Y}=\varphi X_{\mathrm{s}} Y_{\mathrm{s}}+$ $(1-\varphi) X_{\ell} Y_{\ell}$, where subscripts $s$ and $\ell$ are solid and liquid phases, respectively. The values of all constants are given in Table 1.

\section{Salt diffusion}

We use Fick's second law (e.g. Crank, 1979) for salt diffusion and assume that diffusion occurs only among liquid cells, i.e.

$$
\frac{\partial}{\partial t} S(\mathbf{r}, t)=D \nabla^{2} S(\mathbf{r}, t)
$$

where $D$ is the molecular mass diffusivity. In the present model, fluid dynamics has not been considered, i.e. turbulent ocean mixing is thus not simulated. As diffusion is the only method to transfer salt in the system, we compensate for the effect of fluid transport by increasing the value of $D$ to be greater than that for molecular diffusion alone (Hahn-Woernle, 2011) and we call this the effective mass diffusivity $D_{\text {eff }}$.

\section{Liquidus relation}

The freezing temperature of sea water (Dinniman and others, 2007), which is the linearized version of Foldvik and Kvinge (1974), is

$$
T_{\mathrm{L}}(S)=T_{\mathrm{m}}-\Gamma S,
$$

where $T_{\mathrm{m}}$ is the surface freezing point. The liquidus slope $\Gamma$ $=0.057^{\circ} \mathrm{C}$. Note that the depth dependence has been omitted from this relation because the system of interest is at a shallow depth.

\section{NUMERICAL IMPLEMENTATION OF THE MODEL}

A full explanation of the method is given by Wongpan (2013), with an outline presented here. 


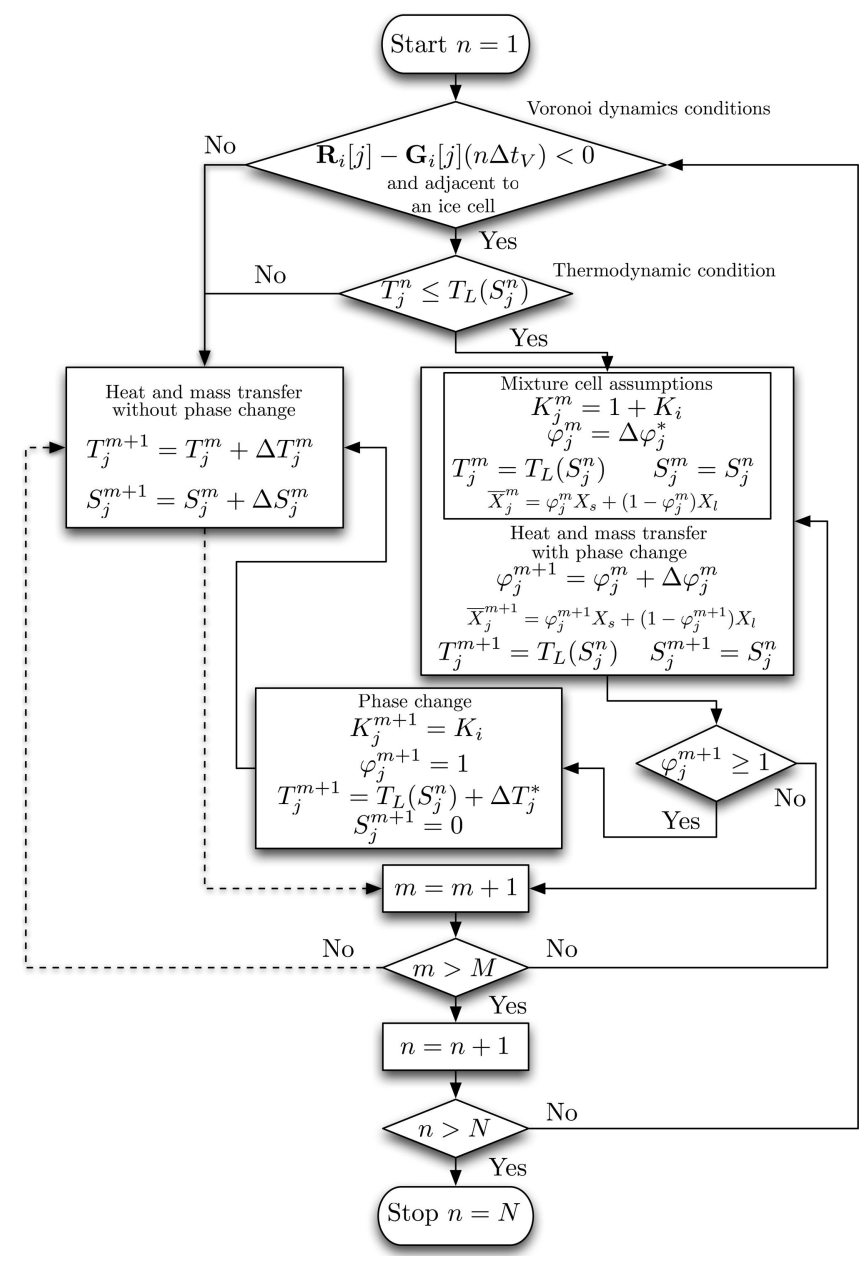

Fig. 4. Flow chart showing the numerical steps. Note that if a process enters the $m=m+1$ box on a dashed line, and if the exit logic from $m>M$ is no, then the logic follows the dashed line when it exits $m>M$.

In Ohashi and others (2004), Dempsey (2008) and Dempsey and others (2010), the only criterion for phase change from liquid to solid is the Voronoi dynamics condition (Eqn (2)) which is given in discretized form in Eqn (8). The Voronoi dynamics condition for cell $j$ with respect to the seed ice crystal $i$ at time $n \Delta t_{V}$ is

$$
\mathbf{R}_{i}[j]-\mathbf{G}_{i}[j]\left(n \Delta t_{\mathrm{V}}\right)<0,
$$

where cell $j$ is liquid at time $n \Delta t_{\mathrm{V}}$ (i.e. $K_{j}^{n}=1$ ). In addition, cell $j$ is adjacent to at least one ice cell with characteristic number $0<K_{i}<1$. Note that different characteristic numbers distinguish between different crystals.

Kawano and Ohashi (2009) add a thermodynamic condition to their 2-D model, where

$$
T_{j}^{n} \leq T_{\mathrm{L}}\left(S_{j}^{n}\right),
$$

where $T_{j}^{n}$ and $S_{j}^{n}$ are respectively temperature and salinity at position $j$ and time $n \Delta t_{V}$, and $T_{L}$ is given by Eqn (7). Heat and mass transfer are implemented without latent heat during a phase change (Kawano and Ohashi, 2009), which is unrealistic. Later, Hahn-Woernle (2011) included latent heat in a 2-D model with supercooled water, but a temperature gradient was not taken into account.

In our model, we include all features from previous models, and extend them to 3-D with lateral periodic boundary conditions. We also add an interim phase to the model, called mixture cells, to make it easier to include latent heat.

The program runs in two loops (Fig. 4), the outside Voronoi loop and the inside heat and mass transfer loop. The corresponding time steps for each loop are $\Delta t_{\mathrm{V}}$ and $\Delta t_{\mathrm{S}}$ respectively. Assuming that we run the simulation for a period of $\tau=N \Delta t_{\mathrm{V}}$, the outside loop runs from $n=1$ to $N$ steps. For each time step $\Delta t_{\mathrm{V}}$, the inside loop runs from $m=1$ to $M$ steps. In short, $\tau=M N \Delta t_{\text {s }}$.

Kawano and Ohashi (2009) used a single time step for Voronoi dynamics and heat and mass transfer. However, in our simulation, we decided to use two time steps to avoid checking the Voronoi dynamics condition at every iteration and to enable us to choose a larger $\Delta t_{\mathrm{V}}$, to span simulation times from seconds to a daily scale.

In this simulation, we use an explicit method to solve the partial differential equation because it is easier to implement. However, the downside of this method is the stability. The size of this $\Delta t_{\mathrm{S}}$ has to be set to be smaller than the limit determined from Courant and others' (1967) conditions.

When the simulation starts, the crystal is seeded at position $i$ in the domain $\Omega$ with its characteristic value $K_{i}$. The displacement of other cells with respect to this seed $i$ and the growth function are kept in matrices $\mathbf{R}_{i}$ and $\mathbf{G}_{i}$, and referred to as $\mathbf{R}_{i}[j]$ and $\mathbf{G}_{i}[j]$ respectively. The Voronoi dynamics inequality of any cell $j$ with respect to crystal seed $i$ at time $n \Delta t_{V}$ is given by Eqn (8). By definition, since $\mathbf{R}_{i}[i]$ is always zero, i.e. it is the displacement to itself, then this inequality is also valid for the seed cell at any time.

From $n \Delta t_{V}$ to $(n+1) \Delta t_{V}, \Delta t_{V}$ is further discretized and runs from $m=1$ to $M$ iterations. Any temperature $T$ and salinity $S$ of cell $j$ at time $m \Delta t_{S}$ can be denoted as $T_{j}^{m}$ and $S_{j}^{m}$ respectively, and updated for each iteration by the heat and mass transfer without phase change equations

$$
T_{j}^{m+1}=T_{j}^{m}+\Delta T_{j}^{m},
$$

and

$$
S_{j}^{m+1}=S_{j}^{m}+\Delta S_{j}^{m},
$$

where $\Delta T_{j}^{m}$ and $\Delta S_{j}^{m}$ are given in Wongpan (2013).

When $m=M$, the Voronoi dynamics condition is checked for each cell. If cell $j$ passes this condition its temperature will be compared with its corresponding liquidus temperature (Eqn (9)), which we call the thermodynamic condition.

If this condition holds, the solidification process starts. The characteristic number of this cell $j$ at step $n\left(K_{j}^{n}\right)$ changes from 1 (liquid) to $1+K_{i}$ (mixture). The solid fraction residual $\Delta \varphi_{j}^{*}$ is calculated from

$$
\Delta \varphi_{j}^{*}=\frac{T_{\mathrm{L}}\left(S_{j}^{n}\right)-T_{j}^{n}}{\left(\rho_{\mathrm{s}} L\right) /\left(\rho_{\ell} C_{\ell}\right)} .
$$

In the heat and mass transfer loop, the temperature for this cell is set equal to the liquidus temperature during solidification $T_{j}^{m}=T_{\mathrm{L}}\left(S_{j}^{n}\right)$. In order to maintain a constant liquidus temperature, the salinity is required to be constant, i.e. $S_{j}^{m}=S_{j}^{n}$. However, salt is rejected continuously from the mixture cell due to the increase in solid (ice) fraction. If there are no liquid cells to absorb salt from this cell, the solidification process stops and the characteristic number of this cell will be set to 2, which is representative of a brine cell. At step $m+1$, the solid fraction accumulates, 
according to

$$
\varphi_{j}^{m+1}=\varphi_{j}^{m}+\Delta \varphi_{j}^{m},
$$

and it is checked whether

$$
\varphi_{j}^{m+1} \geq 1
$$

Physical constants are updated; that is $\bar{X}_{j}^{m+1}=\varphi_{j}^{m+1} X_{\mathrm{s}}+$ $\left(1-\varphi_{j}^{m+1}\right) X_{\ell}$.

If Eqn (14) is true, the phase of the cell changes. First, the temperature residual is calculated from the difference of $\varphi_{j}^{m+1}$ from 1,

$$
\Delta T_{j}^{*}=\left(L / C_{\mathrm{s}}\right)\left(1-\varphi_{j}^{m+1}\right),
$$

and this is added to the liquidus temperature of that cell:

$$
T_{j}^{m+1}=T_{L}\left(S_{j}^{n}\right)+\Delta T_{j}^{*} .
$$

Then $\varphi_{j}^{m+1}$ is reset to 1 . The salinity of this cell is set to zero, and the characteristic number is changed from $1+K_{i}$ (mixture) to $K_{i}$ (solid). On the next step, this cell will be redirected to the heat and mass transfer without the phase change scheme. All the processes above are sketched as a flow chart (Fig. 4). The way we take residuals in temperature and solid fraction into account is similar to an algorithm, called the heat integration method (Dusinberre, 1945).

\section{MODEL RESULTS AND DISCUSSIONS Validation: Stefan problem}

Here we perform simulations to evaluate the accuracy of our code, and to carry out sensitivity experiments by varying the effective mass diffusivity $D_{\text {eff }}$ for each run. To do this, we set up the domain $\Omega$ to match the situation of a onedimensional (1-D) solution (the Stefan problem) as described in Worster (1986).

To match the Stefan problem, which describes 1-D heat transfer with phase change, the domain has the property that $x=y \rightarrow \infty$ and $z$ is finite. We apply periodic boundaries on the $x-y$ plane to achieve the former property. The lengths of the periodic simulation box in the $x, y$, and $z$ directions are $I_{x}, I_{y}$ and $I_{z}$. We set $I_{z}$ to a finite length to satisfy the latter property. We perform the simulation in a domain with dimensions $I_{x}=I_{y}=0.01 \mathrm{~m}$, and $I_{z}=1.0 \mathrm{~m}$, using a uniform grid with cell length $\Delta h=\Delta x=\Delta y=\Delta z=0.001 \mathrm{~m}$.

In the Stefan problem, a slab of sea ice grows downwards by heat loss to the atmosphere. To do this, we place an ice slab with temperature $T_{\text {top }}=-5^{\circ} \mathrm{C}$ at $z=0.001 \mathrm{~m}$. The rest of the domain is sea water with uniform salinity $S_{\text {bot }}=35.16$. Before the simulation starts, an advancing interface is introduced to the domain at position $z=0.002 \mathrm{~m}$, causing the sudden rejection of salt to all cells in the plane $z=0.003 \mathrm{~m}$ with salinity 70.32 . Then the simulation begins.

The Voronoi front (Fig. 3) of the advancing interface has a growth speed $g_{\text {int }}=1.0 \times 10^{-5} \mathrm{~m} \mathrm{~s}^{-1}$ in Eqn (4). By setting $\Delta t_{\mathrm{V}}=10 \mathrm{~s}, g_{\text {int }} \Delta t_{\mathrm{V}}<\Delta h$ which is another requirement of Voronoi dynamics (Kawano and Ohashi, 2009; Dempsey and others, 2010). All simulations in this section run for $1.6 \times 10^{4} \Delta t_{V}$, which is equivalent to $1.6 \times 10^{5} \mathrm{~s}$ or $\sim 2$ days.

The thermodynamic set-up has $S_{\text {bot }}=35.16$ and a freezing point of $T_{\mathrm{L}}\left(S_{\text {bot }}\right)=-1.91^{\circ} \mathrm{C}(\operatorname{Eqn}(7))$. We set $T_{\text {bot }}=$ $-1.50^{\circ} \mathrm{C}$. We simulate four cases by varying $D_{\text {eff }}=\nu D$ over four orders of magnitude, ranging from $6.8 \times 10^{-10}$ to $6.8 \times 10^{-7} \mathrm{~m}^{2} \mathrm{~s}^{-1}$ with $\nu=\{1,10,100,1000\}$.

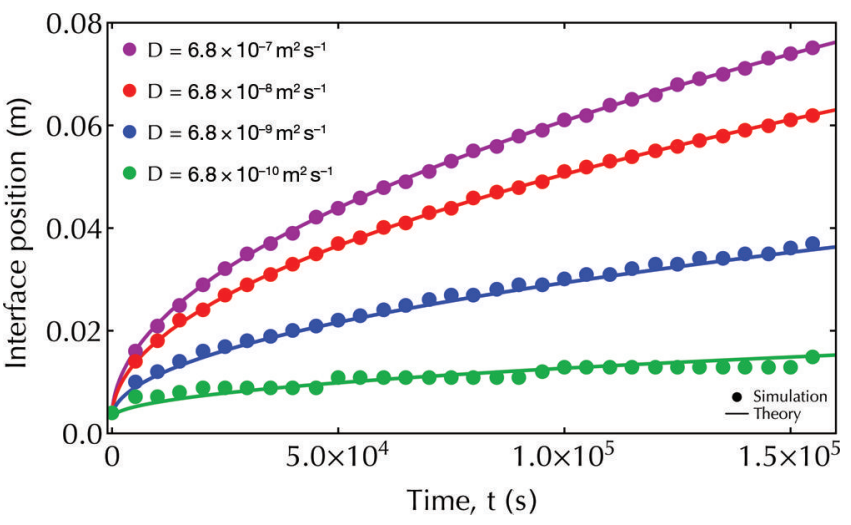

Fig. 5. Interface position versus time. Analytical solutions (Worster, 1986) are plotted with solid lines, while simulation results are plotted with filled circles.

Comparison of our results with theoretical solutions from Worster (1986) confirms the accuracy of our code for each value of $D_{\text {eff }}$ (Fig. 5). We select $D_{\text {eff }}=100 D=6.8 \times$ $10^{-8} \mathrm{~m}^{2} \mathrm{~s}^{-1}$ for all further simulations. This is of the same order of magnitude as applied by Vancoppenolle and others (2010) and Jeffery and others (2011) in modeling the transport of tracers in sea ice.

\section{A single ice flux event from the ocean}

Having evaluated the simulation code in the previous subsection, we now explore two scenarios that are likely to occur in ice-shelf-affected waters. In scenario 1, a flux of tiny seed crystals arrives at the base of the sea-ice cover in a single event. They then grow due to heat loss upwards through the sea ice, as well as to the supercooled ocean. Scenario 2 begins with the formation of a rough ice/water interface, by seeding and growing ice crystals as in scenario 1. After a short time, a continuous flux of crystals is introduced. The advancing interface (driven by heat loss to the atmosphere) grows from the upper domain to freeze the crystals in place to become incorporated platelet ice.

In this section, we assume that a flux of seed ice crystals arrives from the ocean as a single event, under a top-chilled, flat sea-ice cover. These crystals are assumed to be small ( $1 \mathrm{~mm}$ diameter) and to have random positions and orientations. Then they grow locally and we expect a subice platelet layer to form and increase in solid fraction. Observations show that without a continuous supply of loose ice crystals, geometric selection plays a major role, and eventually resumed columnar fabric forms (Dempsey and others, 2010; Dempsey and Langhorne, 2012).

We set a domain $\Omega$ with a total number of cells $\left(N_{x} \times\right.$ $\left.N_{y} \times N_{z}\right)=100 \times 100 \times 100$ cells, i.e. the model resolution is $0.001 \mathrm{~m}$. In order to simulate the growth of a thin layer at the base of a $1 \mathrm{~m}$ thick sea-ice cover, initial and boundary conditions are set with $T_{\text {top }}=-2.5^{\circ} \mathrm{C}, T_{\text {bot }}=-1.96^{\circ} \mathrm{C}$, $S_{\text {top }}=0, S_{\text {bot }}=35.16$ and $D=6.8 \times 10^{-8} \mathrm{~m}^{2} \mathrm{~s}^{-1}$ to match observations within the sub-ice platelet layer from Robinson and others (2014). The initial temperature of each crystal is set to $T_{\mathrm{L}}\left(S_{\text {bot }}\right)=-1.91^{\circ} \mathrm{C}$.

In this simulation, we introduce 120 ice crystals, each of $1 \mathrm{~mm}$ diameter and with random $\mathrm{c}$-axes and seed positions, to the top $10 \%$ of the domain, or equivalently in a region $0.01 \mathrm{~m}$ thick. Note that to compensate the effect of fluid dynamics and oceanic turbulence in the entirely liquid 


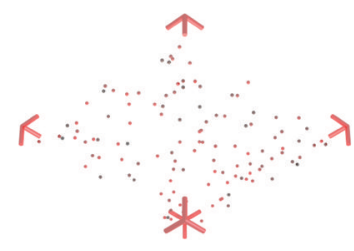

$k$

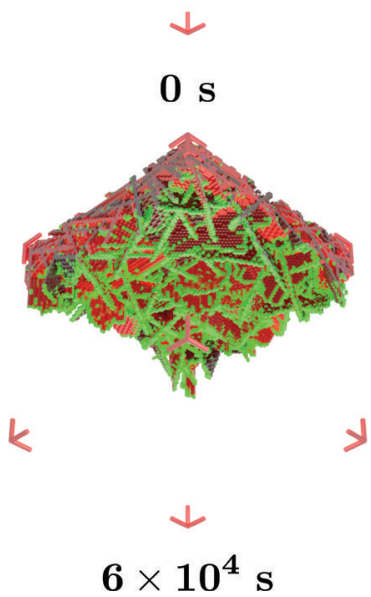

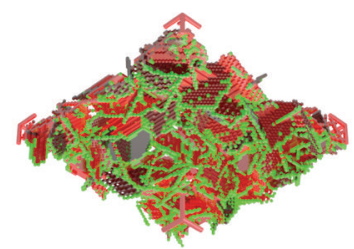

$k$

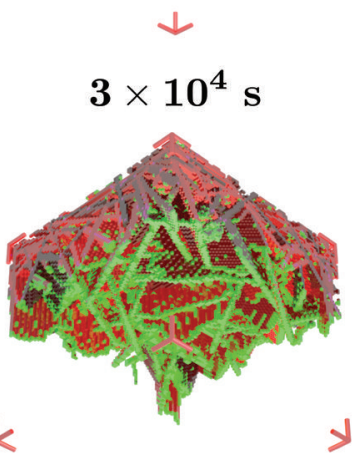

$\downarrow$

$9 \times 10^{4} \mathrm{~s}$
Fig. 6. The ice structure at $0 \mathrm{~s}, 3 \times 10^{4} \mathrm{~s}, 6 \times 10^{4} \mathrm{~s}$ and $9 \times 10^{4} \mathrm{~s}$ following a single ice flux event from the ocean. Ice viewed from below and growing downwards. Different shades of red mean different platelet crystals. Bright green and magenta represent mixture and brine cells respectively.

region beneath the growing sub-ice platelet layer, in this simulation we reset the salinity and temperature to $S_{\text {bot }}$ and $T_{\text {bot. }}$. The growth function of these platelet crystals is oblate spheroidal (Eqn (3)). We set $g_{\mathrm{b}}=5.0 \times 10^{-7} \mathrm{~m} \mathrm{~s}^{-1}$, which is the same order of magnitude as the growth speed of the tip of an ice platelet reported by Smith and others (2012). The aspect ratio $\alpha=30$ (Dempsey and others, 2010) and, automatically, $g_{c}=g_{b} / 30$. The simulation runs for $t=9 \times 10^{3}$ steps or $9 \times 10^{4} \mathrm{~s}$, which is $\sim 1$ day.

First, we consider the structure of the modeled platelet ice. A total of 120 platelet crystals start from the size of one cell and become disc-like shapes at $3 \times 10^{4} \mathrm{~s}$ (Fig. 6). The mixture cells are on the rim of each crystal. At $6 \times 10^{4} \mathrm{~s}$, the platelet crystals interact with each other and mixture cells begin to form a plane, and to grow as a layer. At $9 \times 10^{4} \mathrm{~s}$, the crystals are thicker, causing a wider layer of mixture cells.

To gain a better understanding of the 3-D results, we consider the profiles found by averaging parameters at each depth. We display solid-fraction, salinity and temperature profiles at intervals of $3 \times 10^{4} \mathrm{~s}$ (Fig. 7). In this porous, subice platelet layer, the salinity exhibits a C-shaped profile which is a well-known characteristic of landfast, congelation sea ice. Salt diffuses from the growing sub-ice platelet layer towards the underlying liquid, so that the overall ice salinity decreases with time as expected.

\section{An advancing interface and a continuous ice flux from the ocean}

In describing the second scenario, we introduce a continuous deposition of platelet crystals from the ocean to the sub-ice platelet layer. In addition, we include the incorporation of platelet crystals by an advancing interface to form incorporated platelet ice (Smith and others, 2001; Gough and others, 2012a; Fig. 8). A continuous flux of ice crystals is expected to play an important role in the resulting crystal orientations (Dempsey and others, 2010), noting that the previous work did not include heat and mass transfer.

This simulation is designed to model the western side of McMurdo Sound where a continuous flux of ice crystals seems to be deposited from the underlying water column during the growth of a sea-ice cover (Gow and others, 1998). This scenario represents a flux of ice crystals from the ocean while sea ice grows rapidly. We select a growth rate of $2.2 \times 10^{-2} \mathrm{~m} \mathrm{~d}^{-1}$ which is appropriate for thin ice of $\sim 0.25 \mathrm{~m}$ thickness (Leonard and others, 2006), so the simulation has an advancing interface of $g_{\text {int }}=2.5 \times$ $10^{-7} \mathrm{~m} \mathrm{~s}^{-1}$. The simulation begins by establishing a rough interface from seed crystals as in scenario 1 . We set $g_{b}=5.0 \times 10^{-7} \mathrm{~m} \mathrm{~s}^{-1}$, causing the diameter of the seed crystals at $3 \times 10^{4} \mathrm{~s}$ to have grown to $\sim 30 \mathrm{~mm}$. This is about three times larger than the diameter of the crystals to be deposited. Thus the deposited crystals can enter gaps between the enlarged seed crystals, and together they form the sub-ice platelet layer (Fig. 8). We start the deposition at

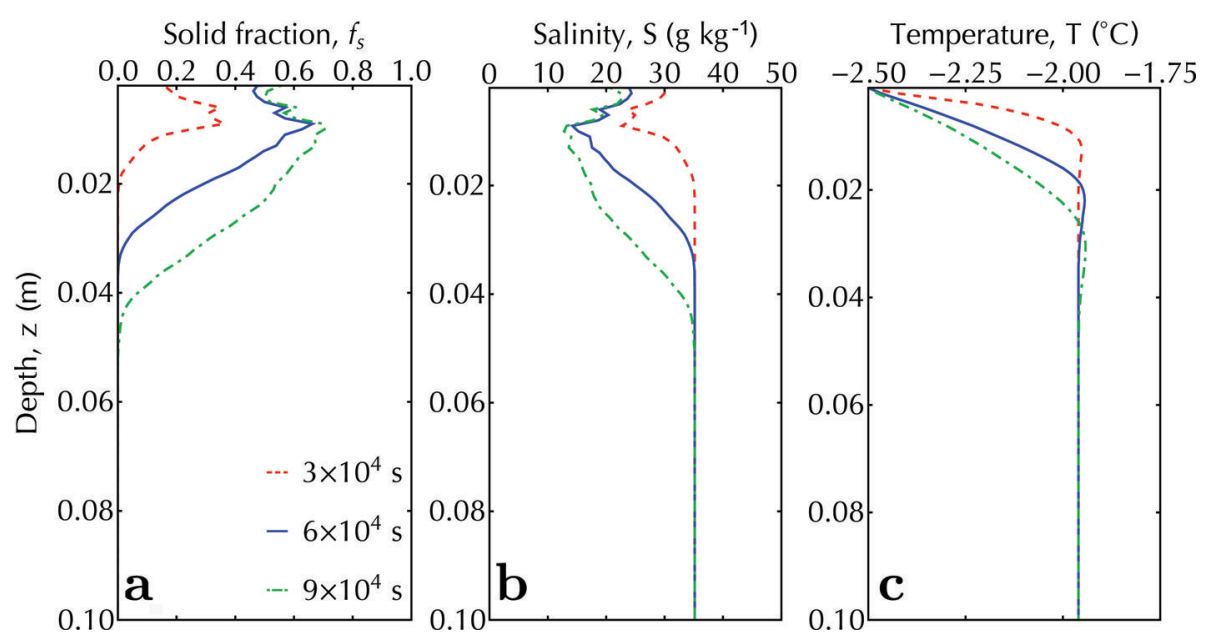

Fig. 7. Solid-fraction (a), salinity (b) and temperature (c) profiles for a single ice flux event from the ocean. Red, blue and green are profiles at $3 \times 10^{4}, 6 \times 10^{4}$ and $9 \times 10^{4}$ s, respectively. 


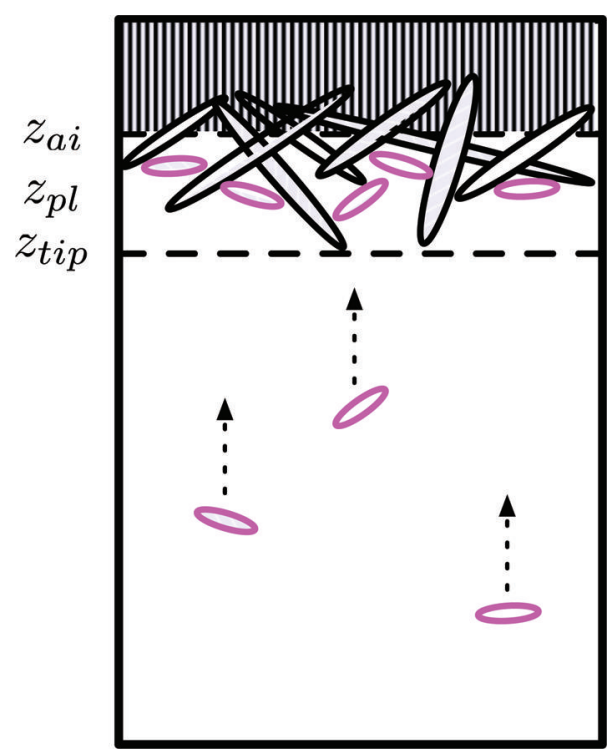

Fig. 8. Ice crystals float up to deposit onto the layer of platelet crystals which have grown beneath the ice bottom, and together they form the sub-ice platelet layer. The ice bottom, initially at $z_{\mathrm{a} i}$ is also moving downwards due to heat loss to the atmosphere. This is referred to as the advancing interface $z_{\mathrm{a} i}$. The tip of the sub-ice platelet layer is at position $z_{\text {tip }}$ and the distance between $z_{\mathrm{a} i}$ and $z_{\text {tip }}$ is referred to as $z_{\mathrm{pl}}$.

$3 \times 10^{4}$ s by launching one ice crystal with average diameter (l) $10 \mathrm{~mm}$ every ten steps or $100 \mathrm{~s}$. For deposition, we use the algorithm of Dempsey and others (2010). Therefore the growth function in the basal plane $\left(G_{b}\right)$ of each deposited crystal is modified to include the morphology of the crystals as observed under sea ice. The last platelet crystal arrives at $6 \times 10^{4} \mathrm{~s}$. In total, there are 300 platelet crystals deposited under the existing sub-ice platelet layer formed by the growth of the 120 seed crystals. The simulations run for $9 \times 10^{4} \mathrm{~s}$ as in the previous subsection.

For this set-up, the ice flux from the ocean is $\Phi=(1 / A)(\mathrm{d} N / \mathrm{d} t)$ where $A$ is the area beneath the sea ice and $\mathrm{d} N / \mathrm{d} t$ is the number of ice crystals rising to the ice base per second. With $A=0.1 \times 0.1 \mathrm{~m}^{2}$ and $\mathrm{d} N / \mathrm{d} t=1 / 100$ crystal $\mathrm{s}^{-1}, \Phi=9 \times 10^{4}$ crystals $\mathrm{m}^{-2} \mathrm{~d}^{-1}$ are accumulated. If we assume that a sub-ice platelet layer has a uniform solid fraction $f_{\mathrm{s}}=0.25$ (Smedsrud and Skogseth, 2006; Gough and others, 2012a), we can calculate the critical ice flux which will allow a sub-ice platelet layer to form, $\Phi_{\text {crit }}=\left(f_{\mathrm{s}} / v_{\mathrm{pl}}\right) g_{\text {int }}$ (Dempsey and others, 2010). Here $v_{\mathrm{pl}}$ is the average volume of each ice platelet, which equals $(4 / 3) \pi(I / 2)^{3} / \alpha$. We find $\Phi_{\text {crit }}$ is $31 \times 10^{4}$ crystals $\mathrm{m}^{-2} \mathrm{~d}^{-1}$. Thus, the simulated ice crystal flux is slightly less than the critical ice flux. This means that if the simulation (Fig. 9) had run for a longer time the sub-ice platelet layer would have been consumed by the advancing interface (Dempsey and others, 2010).

Note that, as expected, the inclusion of an advancing interface causes the solid fraction to be in the range $0.8-1$ at the top of the simulation domain (Fig. 10a). In this region, the salinity (Fig. 10b) is $\sim 10$ as observed in such systems (Gough and others, 2012b). The final scene of the simulated sub-ice platelet layer (Fig. 11) is qualitatively similar to the photographed sub-ice platelet layer (courtesy A.R. Mahoney and A.J. Gough) from McMurdo Sound, Antarctica, in 2009.

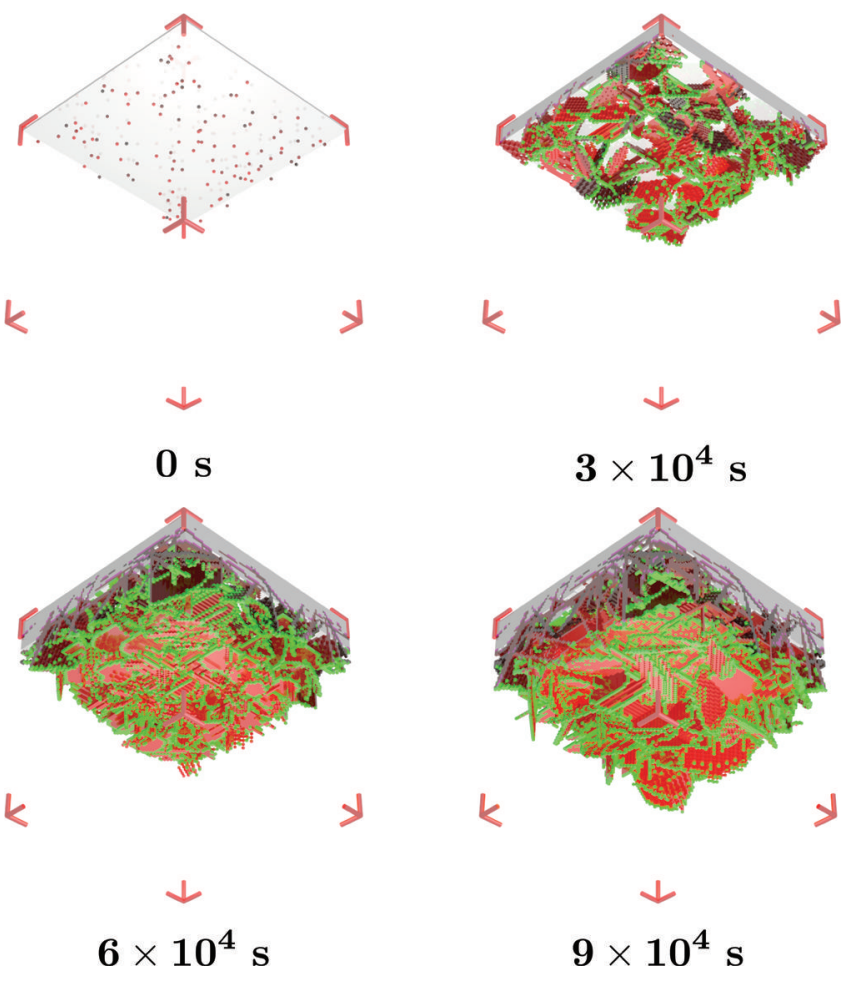

Fig. 9. The ice structure at $0 \mathrm{~s}, 3 \times 10^{4} \mathrm{~s}, 6 \times 10^{4} \mathrm{~s}$ and $9 \times 10^{4} \mathrm{~s}$ of an advancing interface and a continuous ice flux (crystal diameter $10 \pm 1 \mathrm{~mm}$ ) from the ocean. Ice viewed from below and growing downwards. Different shades of red mean different platelet crystals. Bright green and magenta represent mixture and brine cells respectively.

\section{Fabric of platelet ice: simulation versus observation}

In examining the crystal orientation and diameter distributions predicted by the simulation for the two scenarios described above, the development of crystal fabrics following a single ice flux event from the ocean (Fig. 12a) is analysed. In this scenario we start from isotropy because the crystals are seeded randomly under the sea-ice cover. These grow without any additional platelet flux until the crystals begin to impinge on each other at $3 \times 10^{4} \mathrm{~s}$. Geometric selection therefore forces the $c$-axis orientation towards a girdle regime, in which $c$-axes lie predominantly in the horizontal plane, without a preferred direction in that plane. The transition from an isotropic fabric at small depths, to a girdle regime at greater depths, is characteristic of the development of platelet ice towards resumed columnar ice (Fig. 12a). This is in agreement with in situ observations (Gough and others, 2012a) and earlier simulations without heat and mass transfer (Dempsey and others, 2010; Dempsey and Langhorne, 2012).

The crystal diameter is defined as the major axis of the oblate spheroid, and all crystals introduced to the simulation as seed crystals are included in this distribution (Fig. 13a). Thus the figure may be regarded as representing the distribution of crystal diameters in a sub-ice platelet layer. The increase in diameter with time is evident, leading to crystals with diameters in excess of $50 \mathrm{~mm}$. Such crystals are not unusual beneath sea ice abutting an ice shelf (Gow and others, 1998).

For the second scenario (Fig. 8), when ice crystal deposition from the ocean occurs continuously, the trajectories of the crystal fabric are confined to the isotropic 


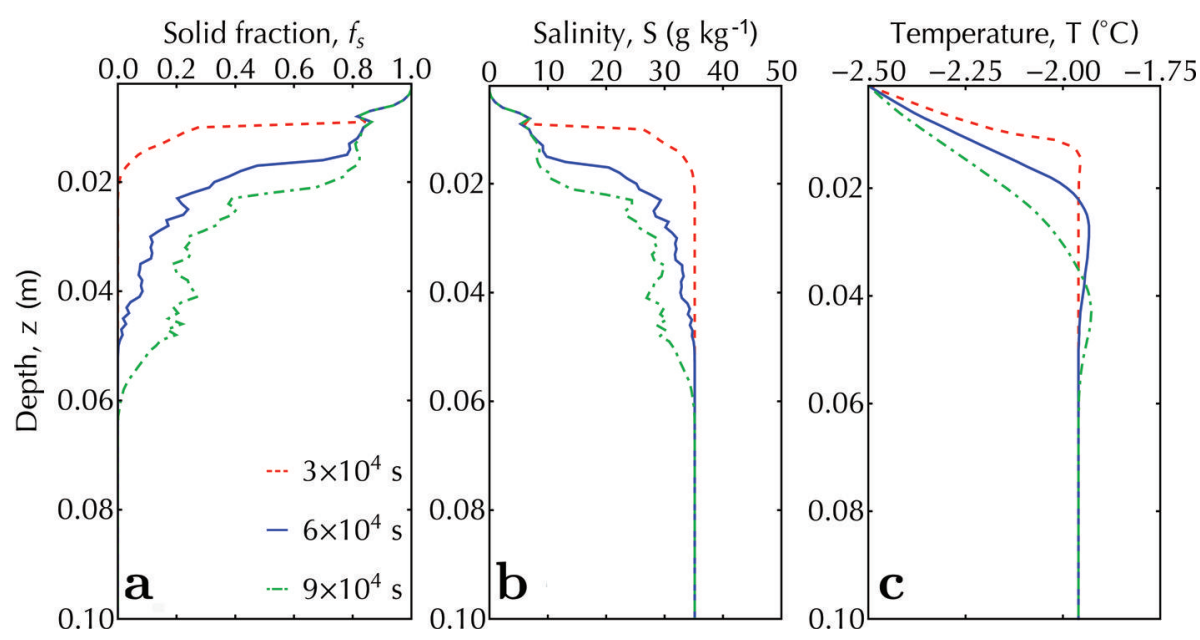

Fig. 10. Solid fraction (a), salinity (b) and temperature (c) profiles for an advancing interface and a continuous ice flux (crystal diameter $10 \pm 1 \mathrm{~mm}$ ) from the ocean. Red, blue and green are profiles at $3 \times 10^{4}, 6 \times 10^{4}$ and $9 \times 10^{4} \mathrm{~s}$, respectively.

regime (Fig. 12b). In this case the simulation is designed to model ice growth over $0.045 \mathrm{~m}$ at the base of a thin sea-ice cover under conditions in which a sub-ice platelet layer may only exist temporarily. The crystallographic result is in good agreement with measurements near the top of the sea ice in western McMurdo Sound (Dempsey and others, 2010; K.G. Hughes and others, unpublished information), as well as at the bottom of a thicker sea-ice cover (Gough and others, 2012a).

The crystal diameters are also smaller in the second scenario (Fig. 13b). At $6 \times 10^{4} \mathrm{~s}$, the population of crystal diameters between 10 and $20 \mathrm{~mm}$ dominates due to the continuous deposition of ice crystals from the ocean with diameter $10 \pm 1 \mathrm{~mm}$. This deposition began at $3 \times 10^{4} \mathrm{~s}$ and continued until $6 \times 10^{4} \mathrm{~s}$. After this, crystal deposition to the sub-ice platelet layer ceases. Consequently, the crystals have become larger at time $9 \times 10^{4} \mathrm{~s}$.

\section{Solid fraction of sub-ice platelet layer}

In general, three processes contribute to the solid fraction in incorporated platelet ice: (1) the deposition of ice crystals from the ocean to the base of the sea ice, (2) the growth of

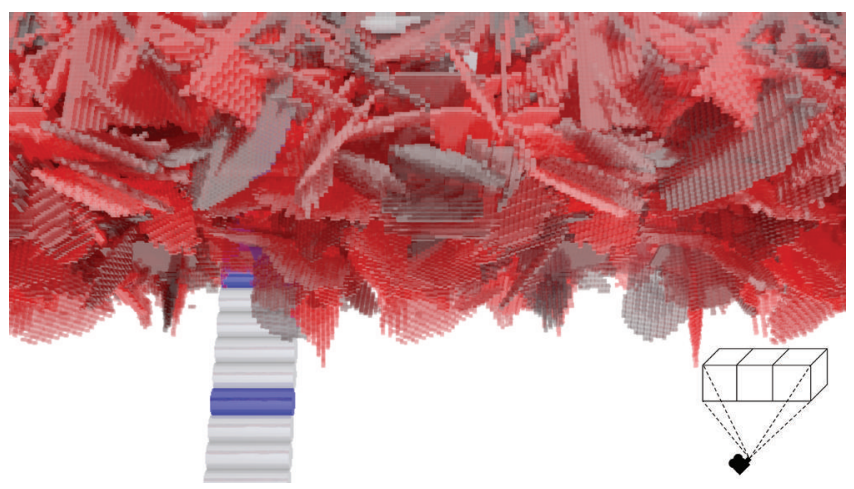

Fig. 11. An example of an underwater scene, at $9 \times 10^{4} \mathrm{~s}$, is shown from a simulation with an advancing interface and a continuous ice flux (crystal diameter $10 \pm 1 \mathrm{~mm}$ ) from the ocean. The scale from blue to blue of the ruler is $0.05 \mathrm{~m}$. In the bottom-right corner, a schematic shows three simulation domains that are connected together to provide a view similar to that from an underwater camera. these crystals in the supercooled water close to the sea-ice base, and (3) their eventual incorporation into the sea ice by the advancing interface (Dempsey and others, 2010). Processes (1) and (2) determine the solid fraction in the sub-ice platelet layer.

The upper bound of the sub-ice platelet layer is set at the advancing interface $z_{\mathrm{a} i}$ (Fig. 8). The position of the tip of a platelet crystal is referred to as $z_{\text {tip }}$. We define the mean solid fraction in a sub-ice platelet layer as

$$
\tilde{f}_{\mathrm{s}}=\frac{1}{z_{\text {tip }}-z_{\mathrm{a} i}} \int_{z_{\mathrm{a} i}}^{z_{\mathrm{tip}}} f_{\mathrm{s}}^{*}(z) \mathrm{d} z,
$$

where $f_{\mathrm{s}}^{*}(z)$ is the horizontally averaged value of the solid fraction at depths from $z_{\mathrm{a} i}$ to $z_{\text {tip }}$. In words, $\widetilde{f}_{\mathrm{s}}$ is the area under the solid fraction profile curve divided by the range of the specified curve.

Scenario 2, with a flux of crystals of $10 \pm 1 \mathrm{~mm}$ diameter, has been shown to display a transitory sub-ice platelet layer. For this case (Fig. 14), we obtain $\widetilde{f}_{\mathrm{s}} \approx 0.22$ which is in good agreement with $0.25 \pm 0.06$ reported by Gough and others (2012a), who deduced solid fraction from measurements of heat flux from ice temperature profiles. It is also in

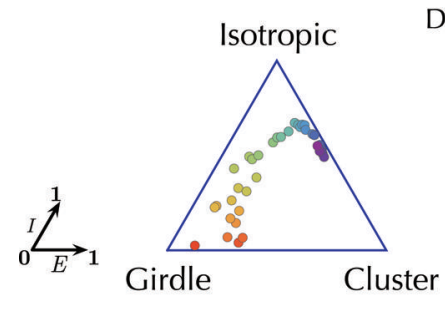

a

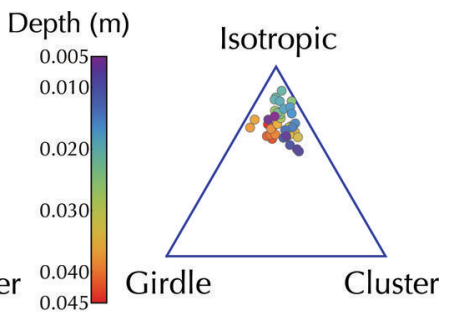

b
Fig. 12. The crystal orientations of (a) a single ice flux event from the ocean and (b) an advancing interface and a continuous ice flux from the ocean are summarized in the ternary plots (Benn, 1994; Gough and others, 2012a). Each point represents $(E, I)$, where $E$ and $I$ are the elongation (which is close to 1 for aligned fabrics) and the isotropy (which is close to 1 for isotropic fabrics) axes, respectively. Depth of each thin section of the simulated sea-ice core is indicated by its colour from the top of the core at $z=0.005 \mathrm{~m}$ (violet) to its bottom at $z=0.045 \mathrm{~m}$ (red). Note that in (b), the crystal orientations of the crystals in the advancing interface are omitted from the plot. 

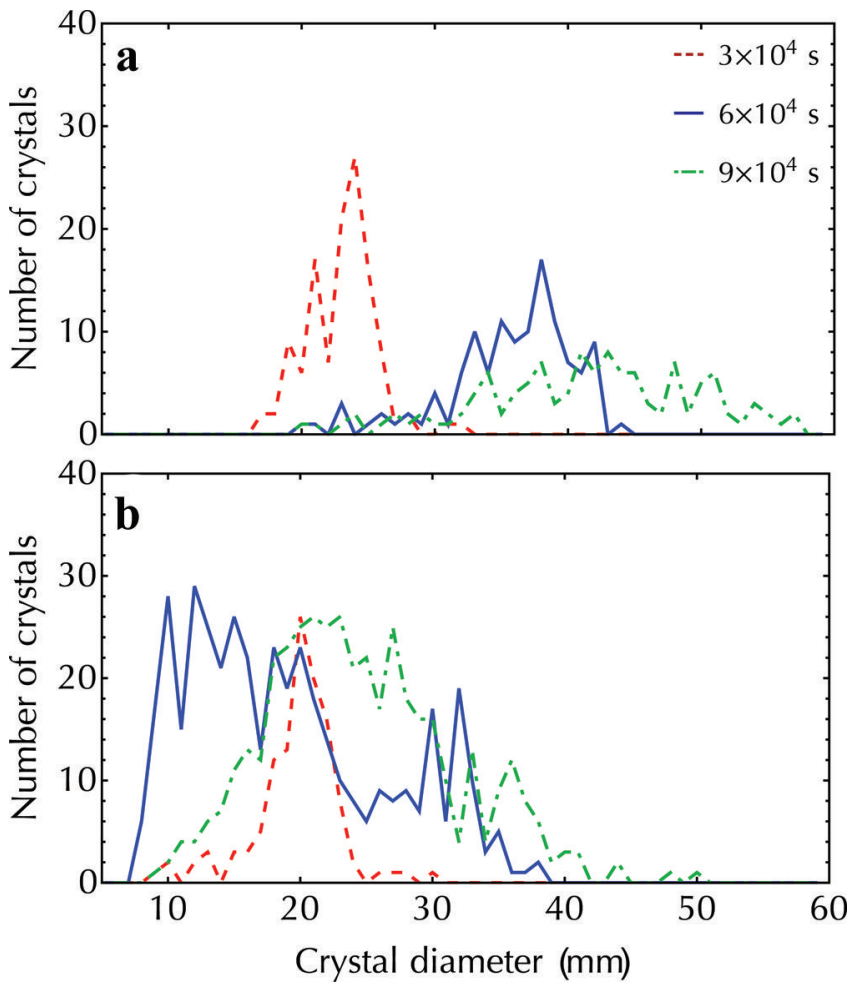

Fig. 13. Distributions of crystal diameter at $3 \times 10^{4}, 6 \times 10^{4}$ and $9 \times 10^{4} \mathrm{~s}(\mathrm{a})$ for a single ice flux event of 120 crystals with uniform diameter of $1 \mathrm{~mm}$ at $0 \mathrm{~s}$ and (b) where an advancing interface and an ice flux from the ocean of 1 crystal every $100 \mathrm{~s}$ is added from $3 \times 10^{4} \mathrm{~s}$ until $6 \times 10^{4} \mathrm{~s}$. A total of 300 crystals, with a diameter selected randomly in the range $10 \pm 1 \mathrm{~mm}$, are added during the continuous ice flux.

agreement with $\widetilde{f}_{\mathrm{s}} \approx 0.25$ for frazil/grease ice samples taken in an active polynya (Smedsrud and Skogseth, 2006).

To examine the effect of crystal diameter we performed a simulation with a continuous flux of ice crystals of diameter $5 \pm 1 \mathrm{~mm}$. This yields $\widetilde{f}_{\mathrm{s}} \approx 0.29$ (Fig. 14). There are a number of reasons why a smaller crystal diameter might produce a higher solid fraction. First we note that the depth of the sub-ice platelet layer is smaller than it is for $10 \mathrm{~mm}$ crystals, leading to a higher solid fraction. In addition, smaller crystals will have a greater packing efficiency than larger crystals. Nonetheless solid fraction appears to be relatively insensitive to the diameter of crystals that impinge on the interface, with a $30 \%$ change in solid fraction resulting from a halving of the crystal diameter.

\section{CONCLUSION}

A simulation based on Voronoi dynamics, and incorporating heat and mass transfer by diffusive processes, has been constructed to predict the solid fraction and crystal orientations in the sub-ice platelet layer. The major limitation is the neglect of fluid dynamics. Our code is evaluated with 1-D solidification, the so-called Stefan problem. We extend the results of Dempsey and others (2010) in order to give a more accurate assessment of the solid fraction in the porous sub-ice platelet layer. Including the two main contributing processes, a flux of ice platelets from the ocean and local growth in the sub-ice platelet layer, we obtain a solid fraction of $\sim 0.22$. This result is in good agreement with the value of $0.25 \pm 0.06$ obtained experimentally by Gough

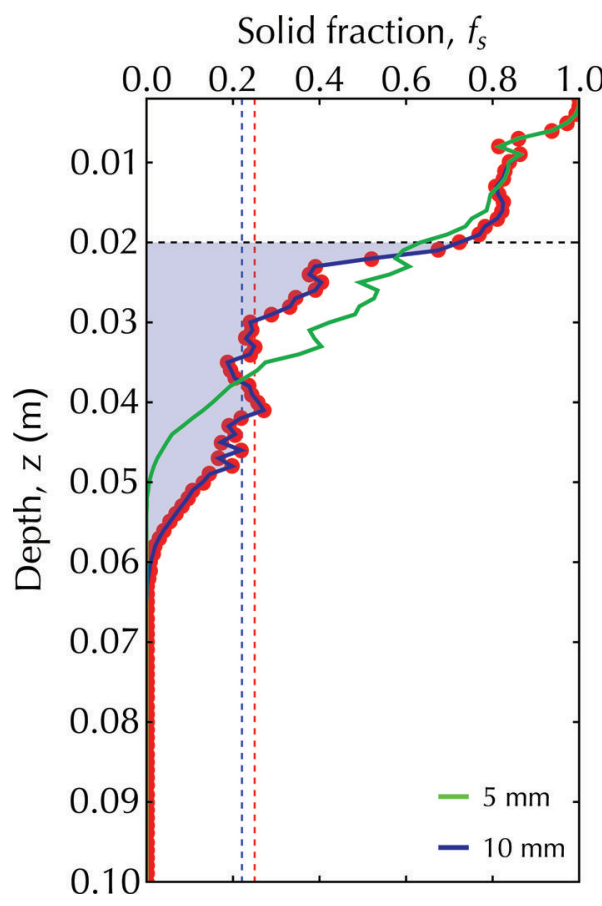

Fig. 14. The solid fraction profile at $9 \times 10^{4} \mathrm{~s}$ for a simulation with a continuous flux of crystals of diameter $10 \pm 1 \mathrm{~mm}$ (red dots). The area under this curve from $z_{\mathrm{a} i}=0.020 \mathrm{~m}$ (horizontal dashed line) to $z_{\text {tip }}=0.061 \mathrm{~m}$ is shaded in blue. Vertical red dashed line marks the solid fraction equal to 0.25 reported by Gough and others (2012a). Vertical blue dashed line identifies the mean solid fraction calculated by Eqn (17). The green line is the solid fraction profile for a simulation with a continuous flux of crystals of diameter $5 \pm 1 \mathrm{~mm}$

and others (2012a). The final contribution from the advancing interface, driven by heat flux to the atmosphere, fills the interstices and increases the solid fraction of the upper part of the sub-ice platelet layer to become close to 1 , forming incorporated platelet ice.

Instead of solving for sea-ice solid fraction by considering solidification of a permeable material, as in mushy layer theory (e.g. Worster, 1986), in this work the growth of individual crystals was simulated. Good agreement between the simulated crystal orientation distributions and the observations of Leonard and others (2006), Dempsey and others (2010) and Gough and others (2012a) has allowed us to verify the simulations. Consequently, we are confident that our model, including the three contributing processes and with enhanced, diffusion-controlled local growth, is a reasonable model of platelet ice formation. This is an important step in understanding the dynamics of the formation of a sub-ice platelet layer because the layer is inaccessible, loose and difficult to sample.

\section{ACKNOWLEDGEMENTS}

P.W. has been supported by a University of Otago publishing bursary. We acknowledge Craig Stevens, Michael Williams and Sarah Wakes for helpful suggestions. The numerical results were simulated on the University of Otago Vulcan cluster. We acknowledge Lars Smedsrud, an anonymous reviewer and the editors, whose suggestions and comments helped improve and clarify earlier versions of the manuscript. 


\section{REFERENCES}

Arrigo KR and Thomas DN (2004) Large scale importance of sea ice biology in the Southern Ocean. Antarct. Sci., 16(4), 471-486 (doi: 10.1017/S0954102004002263)

Benn DI (1994) Fabric shape and the interpretation of sedimentary fabric data. J. Sediment. Res., 64A(4), 910-915 (doi: 10.1306/ D4267F05-2B26-11D7-8648000102C1865D)

Bintanja R, Van Oldenborgh GJ, Drijfhout SS, Wouters B and Katsman CA (2013) Important role for ocean warming and increased ice-shelf melt in Antarctic sea-ice expansion. Nature Geosci., 6(5), 376-379 (doi: 10.1038/ngeo1767)

Courant R, Friedrichs K and Lewy H (1967) On the partial difference equations of mathematical physics. IBM J. Res. Dev., 11(2), 215-234 (doi: 10.1147/rd.112.0215)

Crank J (1979) The mathematics of diffusion. Oxford University Press, Oxford

Dempsey DE (2008) Observation and modeling of platelet ice in McMurdo Sound, Antarctica. (Master's thesis, University of Otago)

Dempsey DE and Langhorne PJ (2012) Geometric properties of platelet ice crystals. Cold Reg. Sci. Technol., 78, 1-13 (doi: 10.1016/j.coldregions.2012.03.002)

Dempsey DE, Langhorne PJ, Robinson NJ, Williams MJM, Haskell TG and Frew RD (2010) Observation and modeling of platelet ice fabric in McMurdo Sound, Antarctica. J. Geophys. Res., 115(C1), C01007 (doi: 10.1029/2008JC005264)

Dinniman MS, Klinck JM and Smith WO (2007) Influence of sea ice cover and icebergs on circulation and water mass formation in a numerical circulation model of the Ross Sea, Antarctica. J. Geophys. Res., 112(C11), C11013 (doi: 10.1029/2006JC004036)

Dusinberre GM (1945) Numerical methods for transient heat flow. ASME Trans., 67(8), 703-712

Foldvik A and Kvinge T (1974) Conditional instability of sea water at the freezing point. Deep-Sea Res., 21(3), 169-174 (doi: 10.1016/0011-7471(74)90056-4)

Gough AJ, Mahoney AR, Langhorne PJ, Williams MJM, Robinson NJ and Haskell TG (2012a) Signatures of supercooling: McMurdo Sound platelet ice. J. Glaciol., 58(207), 38-50 (doi: 10.3189/2012JoG10J218)

Gough AJ, Mahoney AR, Langhorne PJ, Williams MJM and Haskell TG (2012b) Sea ice salinity and structure: a winter time series of salinity and its distribution. J. Geophys. Res., 117(C3), C03008 (doi: 10.1029/2011JC007527)

Gow AJ, Ackley SF, Govoni JW and Weeks WF (1998) Physical and structural properties of land-fast sea ice in McMurdo Sound, Antarctica. In Jeffries $\mathrm{MO}$ ed. Antarctic sea ice: physical processes, interactions and variability. (Antarctic Research Series 74) American Geophysical Union, Washington, DC, 355-374

Haas C and Druckenmiller M (2009) Ice thickness and roughness measurements. In Eicken $H$, Gradinger $R$, Salganek $M$, Shirasawa K, Perovich D and Leppäranta $M$ eds. Field techniques for sea ice research. University of Alaska Press, Fairbanks, AK, 49-116

Hahn-Woernle L (2011) Numerical simulation of sea ice growth. (MSc thesis, ETH Zürich)

Hellmer HH (2004) Impact of Antarctic ice shelf basal melting on sea ice and deep ocean properties. Geophys. Res. Lett., 31(10), L10307 (doi: 10.1029/2004GL019506)

Hillig WB (1959) Kinetics of solidification from nonmetallic liquids. In Kingery WD ed. Kinetics of high-temperature processes. MIT Press, Cambridge, MA, 127-135

Jeffery N, Hunke EC and Elliott SM (2011) Modeling the transport of passive tracers in sea ice. J. Geophys. Res., 116(C7), C07020 (doi: 10.1029/2010JC006527)

Kawano $\mathrm{Y}$ and Ohashi T (2006) Numerical simulation for development of polycrystal microstructure of sea ice and brine formation by salinity concentration. In Proceedings of the 21st International Symposium on Okhotsk Sea and Sea Ice,
19-24 February 2006, Mombetsu, Hokkaido, Japan. Okhotsk Sea and Cold Ocean Research Association, Hokkaido, 95-98

Kawano Y and Ohashi T (2009) A mesoscopic numerical study of sea ice crystal growth and texture development. Cold Reg. Sci. Technol., 57(1), 39-48 (doi: 10.1016/j.coldregions. 2009.02.001)

Kobayashi R (1993) Modeling and numerical simulations of dendritic crystal growth. Physica D, 63(3-4), 410-423 (doi: 10.1016/0167-2789(93)90120-P)

Kolmogorov AN (1949) Kvoprosu o geometricheskom otbore kristallov [Geometric selection of crystals]. Dokl. Akad. Nauk. SSSR, 65(5), 681-684 [Transl. 1976 Cold Regions Research and Engineering Laboratory, Hanover, $\mathrm{NH}]$

Leonard GH, Purdie CR, Langhorne PJ, Haskell TG, Williams MJM and Frew RD (2006) Observations of platelet ice growth and oceanographic conditions during the winter of 2003 in McMurdo Sound, Antarctica. J. Geophys. Res., 111(C4), C04012 (doi: 10.1029/2005JC002952)

Lewis EL and Perkin RG (1986) Ice pumps and their rates. J. Geophys. Res., 91(C10), 11 756-11 762 (doi: 10.1029/JC091 iC10p11756)

Maus S and De la Rosa S (2012) Salinity and solid fraction of frazil and grease ice. J. Glaciol., 58(209), 594-612 (doi: 10.3189/ 2012JoG11J110)

Monaghan JJ, Huppert HE and Worster MG (2005) Solidification using smoothed particle hydrodynamics. J. Comput. Phys. 206(2), 684-705 (doi: 10.1016/j.jcp.2004.11.039)

Naumann AK, Notz D, Håvik L and Sirevaag A (2012) Laboratory study of initial sea-ice growth: properties of grease ice and nilas. Cryosphere, 6(4), 729-741 (doi: 10.5194/tc-6-729-2012)

Ohashi T, Sasaki M and Yoshimura K (2004) A numerical simulation of the development of ice-microstructures. In Proceedings of the 19th International Symposium on Okhotsk Sea and Sea Ice, 22-28 February 2004, Mombetsu, Hokkaido, Japan. Okhotsk Sea and Cold Ocean Research Association, Hokkaido, 180-185

Price D, Rack W, Langhorne PJ, Haas C, Leonard G and Barnsdale K (2014) The sub-ice platelet layer and its influence on freeboard to thickness conversion of Antarctic sea ice. Cryos. Discuss., 8(1), 999-1022 (doi: 10.5194/tcd-8-999-2014)

Robinson NJ, Williams MJM, Stevens CL, Langhorne PJ and Haskell TG (2014) Evolution of a supercooled Ice Shelf Water plume with an actively growing subice platelet matrix. J. Geophys. Res., 119(6), 3425-3446 (doi: 10.1002/2013JC009399)

Smedsrud LH and Jenkins A (2004) Frazil ice formation in an ice shelf water plume. J. Geophys. Res., 109(C3), C03025 (doi: 10.1029/2003JC001851)

Smedsrud LH and Skogseth R (2006) Field measurements of Arctic grease ice properties and processes. Cold Reg. Sci. Technol., 44(3), 171-183 (doi: 10.1016/j.coldregions.2005.11.002)

Smith IJ, Langhorne PJ, Haskell TG, Trodahl HJ, Frew R and Vennell MR (2001) Platelet ice and the land-fast sea ice of McMurdo Sound, Antarctica. Ann. Glaciol., 33, 21-27 (doi: 10.3189/ 172756401781818365)

Smith IJ, Langhorne PJ, Frew RD, Vennell R and Haskell TG (2012) Sea ice growth rates near ice shelves. Cold Reg. Sci. Technol., 83-84, 57-70 (doi: 10.1016/j.coldregions.2012.06.005)

Spittle JA and Brown SGR (1994) A 3D cellular automaton model of coupled growth in two component systems. Acta Metall. Mater., 42(6), 1811-1815 (doi: 10.1016/0956-7151(94)90006-X)

Tan L and Zabaras N (2006) A level set simulation of dendritic solidification with combined features of front-tracking and fixeddomain methods. J. Comput. Phys., 211(1), 36-63 (doi: 10.1016/ j.jcp.2005.05.013)

Vancoppenolle M, Goosse H, de Montety A, Fichefet T, Tremblay B and Tison J-L (2010) Modeling brine and nutrient dynamics in Antarctic sea ice: the case of dissolved silica. J. Geophys. Res., 115(C2), C02005 (doi: 10.1029/2009JC005369)

Wongpan P (2013) Voronoi dynamics simulation of platelet sea ice growth with diffusive heat and mass transfer. (Master's thesis, University of Otago) 